\title{
EDUCAÇÃO AMBIENTAL NA ESCOLA: UM CAMINHO PARA APRIMORAR A PERCEPÇÃO DOS ALUNOS QUANTO À IMPORTÂNCIA DOS RECURSOS HÍDRICOS
}

\author{
Jeane Teresinha de Oliveira ${ }^{1}$ \\ Rita de Cássia Dallago Machado² \\ Everton Mário de Oliveira ${ }^{3}$
}

\begin{abstract}
RESUMO
A educação ambiental é um assunto que deve ser tratado nas escolas, pois, contribui na formação de cidadãos mais aptos a se relacionar de maneira sustentável com os recursos naturais de suas comunidades. Neste sentido, o objetivo deste trabalho foi demonstrar de forma qualitativa a percepção sobre os recursos hídricos e os danos causados a eles em decorrência da agricultura e o desmatamento indisciplinado em áreas de nascentes. A pesquisa foi desenvolvida em uma escola estadual de Mandirituba/PR com 23 alunos de uma turma de 6o ano, revelando, em um primeiro momento, a carência de ações de educação ambiental. Com a aplicação de atividades de sensibilização, a percepção dos alunos melhorou significativamente, demonstrando que as atividades de educação ambiental são instrumentos eficazes para aprimorar a concepção de cada aluno quanto à preservação e o consumo sustentável dos recursos hídricos de suas comunidades induzindo a uma melhor qualidade de vida.
\end{abstract}

PALAVRAS-CHAVE: Sensibilização. Recursos hídricos. Consumo sustentável.

\section{ENVIRONMENTAL EDUCATION IN SCHOOLS : A WAY TO IMPROVE THE PERCEPTION OF STUDENTS AS TO THE IMPORTANCE OF WATER RESOURCES}

\begin{abstract}
Environmental education is a matter that should be dealt with in schools, therefore, contributes to the formation of the fittest citizens to relate sustainably with the natural resources of their communities. In this sense, the objective of this study was to demonstrate qualitatively the perception on water resources and the damage caused to them as a result of agriculture and the undisciplined deforestation in emerging areas. The research was developed at a state school Mandirituba / PR with
\end{abstract}

\footnotetext{
${ }^{1}$ Graduada em Ciências Biológicas, Universidade Tuiuti do Paraná. Email: oliveira.jeane121@gmail.com

${ }^{2}$ Graduada em Biologia, Mestre em Metodologia do Ensino, Docente do curso de Ciências Biológicas na Universidade Tuiuti do Paraná, Rua Sydnei Antônio Rangel Santos, ํo 238 - Santo Inácio, CEP 82010-330, Curitiba - PR. Fone: (041) 3331-7700. Email: rdallagom@gmail.com

${ }^{3}$ Graduado em Geografia, Mestre em Ciência e Tecnologia Ambiental, Universidade Tecnológica Federal do Paraná (UTFPR), Programa de Pós Graduação em Ciência e Tecnologia Ambiental/ PPGCTA/ CEP - 81280-340 - Curitiba - Paraná - Brasil. Email: everton.utp@hotmail.com
} 
23 students of 6th class year, revealing, at first, the lack of environmental education. With the implementation of outreach activities, the students' perception improved significantly, demonstrating that environmental education activities are effective tools to improve the design of each student and to the preservation and sustainable use of water resources in their communities leading to a better quality life.

KEYWORDS: Awareness. Water resources. Sustainable consumption.

\section{EDUCACIÓN AMBIENTAL EN LAS ESCUELAS : UNA MANERA PARA MEJORAR LA PERCEPCIÓN DE LOS ESTUDIANTES EN CUANTO A LA IMPORTANCIA DE LOS RECURSOS HÍDRICOS}

\section{RESUMEN}

La educación ambiental es un asunto que debe ser tratado en las escuelas, por lo tanto, contribuye a la formación de los ciudadanos aptos para relacionarse de manera sostenible con los recursos naturales de sus comunidades. En este sentido, el objetivo de este estudio fue demostrar cualitativamente la percepción sobre los recursos hídricos y de los daños causados a ellos como resultado de la agricultura y la deforestación indisciplinada en áreas emergentes. La investigación se desarrolló en una escuela estatal Mandirituba / PR con 23 estudiantes de sexto año de la clase, que revela, en un primer momento, la falta de educación ambiental. Com

la implementación de actividades de divulgación, la percepción de los estudiantes mejoró significativamente que demuestra que las actividades de educación ambiental son herramientas eficaces para mejorar el diseño de cada estudiante y para la conservación y el uso sostenible de los recursos hídricos en sus comunidades que conduce a una mejor calidad vida.

PALABRAS CLAVE: Conciencia. Los recursos hídricos. El consumo sostenible.

\section{INTRODUÇÃO}

O modelo de desenvolvimento econômico do estado do Paraná foi baseado no estímulo da produção primária, ou seja, a agricultura e a pecuária. Com base na maximização da produção através do aumento de áreas cultivadas, prática que levou a ocupação de quase todo o espaço físico das propriedades rurais, inclusive das matas ciliares (OLIVEIRA et.al, 2013). "O termo mata ciliar significa qualquer formação florestal na margem de cursos d'água" (WWF, 2006).

Segundo Dalzotto e Carniatto (2009) o desmatamento de encostas e das matas ciliares vem contribuindo de forma significativa nas últimas décadas para a diminuição da quantidade e qualidade da água. As matas ciliares degradadas demandam prioridade para as ações de revegetação e/ou enriquecimento, tendo em vista que essas matas tem um papel estratégico na conservação da biodiversidade de flora e fauna e na preservação das águas (NAPPO et al, 2006 apud DALZOTTO E CARNIATTO, 2009). 
Atualmente existem ONGs que são responsáveis por orientar as pessoas de determinadas regiões, quanto à importância de se ter um desenvolvimento sustentável visando à preservação dos recursos naturais de suas comunidades.

\footnotetext{
"A Educação Ambiental é vista como um meio de um indivíduo construir valores sociais para consequentemente possuir um conhecimento e continuando assim habilitado para gerar atitudes e de usar com responsabilidade o que é do povo de fato, essencial à sadia qualidade de vida, contribuindo para um lugar agradável a toda geração futura" (PEDRINI, 1997, p. 9 apud SILVA et al, 2011).
}

Partindo do principio de que "a educação ambiental surge como uma nova forma de encarar o comportamento e o papel do ser humano no planeta Terra" (PINELI et al, 2010) a escola tem importância fundamental, quando se trata de sensibilizar os alunos quanto ao seu papel frente à sociedade, as suas ações e seu comprometimento com a preservação de um recurso essencial a vida no planeta, a água.

Para Layrargues (2006) a educação ambiental deve ser implementada primeiramente nas escolas, pois é nesse ambiente que os menores indivíduos de uma sociedade passam boa parte do tempo e em contato com novos conceitos. $O$ contato com temas relacionados à conservação dos recursos hídricos será melhor assimilado pelos alunos durante essa fase, pois é quando estarão mais aptos a receber conhecimento e formar seu pensamento critico (OLIVEIRA et al, 2013).

O parágrafo primeiro e o inciso VI do artigo 225 da Constituição de 1988 determinam que, o poder público tem a incumbência de promover a educação ambiental em todos os níveis de ensino e a conscientização pública, com vistas à preservação do meio ambiente (BRASIL, 1988).

Para que haja a compreensão e como consequência disso, a sensibilização dos alunos em relação aos recursos hídricos de sua comunidade é de extrema importância que a educação ambiental utilize de atividades que envolvam o aluno em situações de aprendizagem mútua colocando o aluno em um contexto em que o conhecimento seja construído com base em experiências de vida (DALZOTTO e CARNIATTO, 2009), fazendo com que esses pequenos integrantes da sociedade possam ser multiplicadores de conhecimento para a comunidade à sua volta.

Sendo assim, de acordo com Frank (2010) sensibilização, mobilização e capacitação promoveriam um maior envolvimento e disposição a participar e 
cooperar na solução de problemas relativos à água e à sua preservação e os estudos que analisaram percepções sobre impactos ambientais em nascentes de rios em comunidades rurais são escassos (RODRIGUES et al, 2010).

\section{OBJETIVO}

O objetivo do presente trabalho foi analisar a percepção ambiental relacionada à preservação dos recursos hídricos, de alunos em um colégio estadual, localizado nas proximidades de uma nascente preservada, com a finalidade de sensibilizá-los quanto à importância de se manter este local preservado, assim como a mata ciliar. Compreendendo que esta é fundamental à manutenção de um bem tão precioso à existência da vida no planeta.

\section{METODOLOGIA}

A pesquisa foi desenvolvida na comunidade de Areia Branca dos Assis no município de Mandirituba/PR, localizado na Região Metropolitana Sul de Curitiba/PR. Desta pesquisa, participaram 23 alunos com a faixa etária entre 10 e 13 anos e que frequentam uma turma de $6^{\circ}$ ano do colégio estadual.

A primeira etapa da pesquisa foi realizada através de um questionário aplicado aos alunos com perguntas abertas e fechadas referente aos recursos hídricos e impactos causados a eles, como pode ser observado na Figura 1.

Figura 1. Questionário aplicado aos alunos.

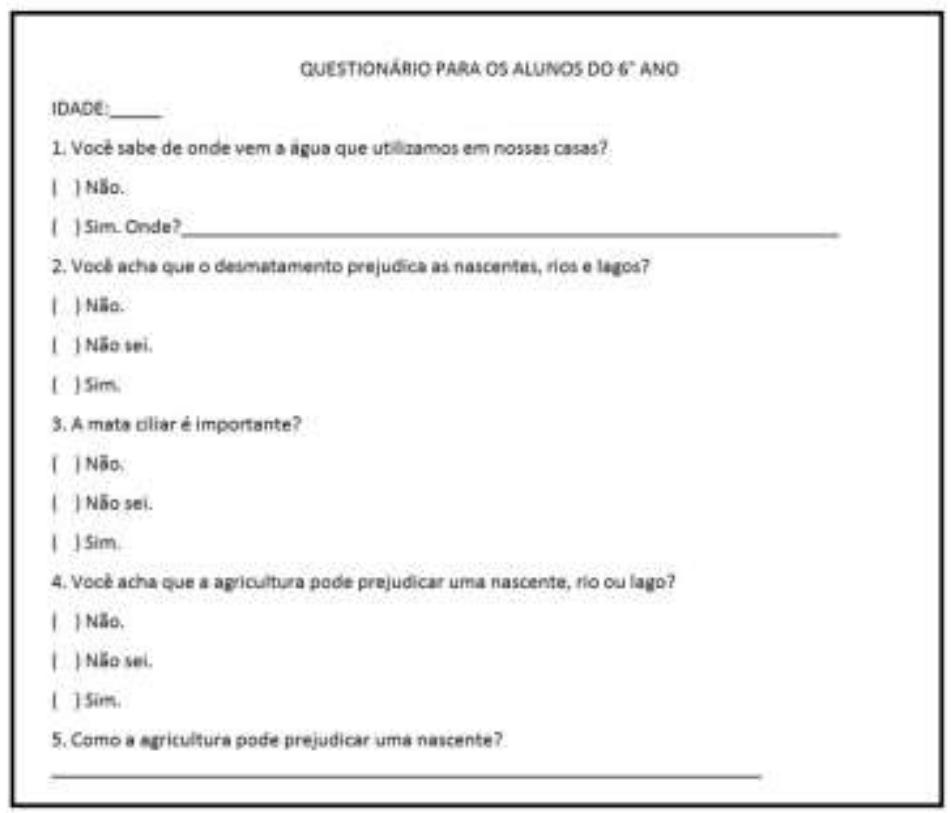

Fonte: Autoria própria, 2013. 
Após a aplicação do questionário, realizou-se uma palestra com temas relacionados à preservação de nascentes e os impactos causados pela agricultura. Já informados da importância de se preservar as nascentes, os alunos desenvolveram, com o auxílio da professora, cartazes de sensibilização para uma exposição aos demais alunos do corpo discente da escola, visando à compreensão destes em relação à importância da preservação dos recursos hídricos de suas comunidades. Conforme Figuras 2 e 3.

Figura 2. Elaboração dos cartazes.

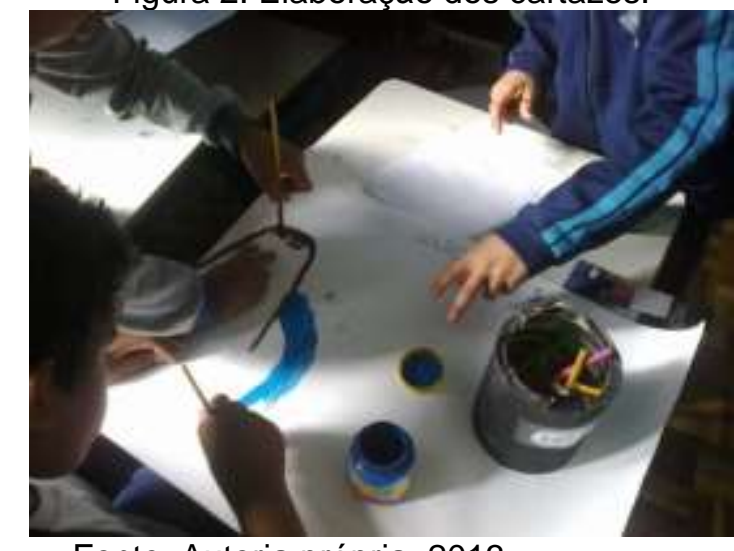

Fonte: Autoria própria, 2013.

Figura 3. Exposição dos cartazes na escola.

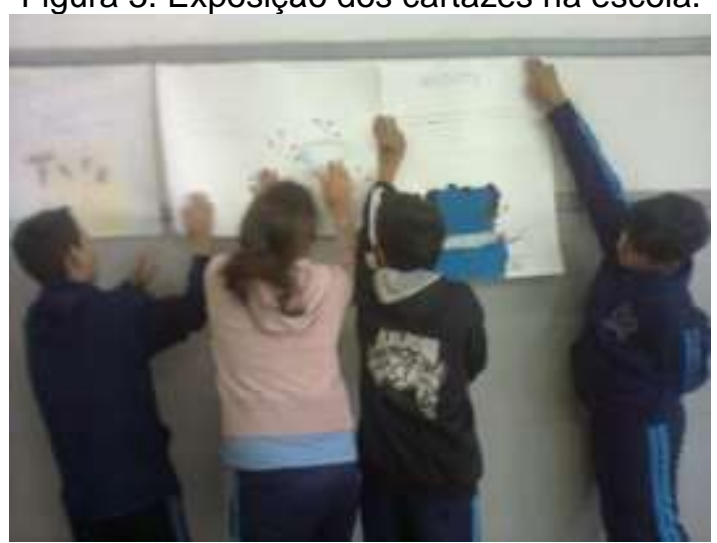

Fonte: Autoria própria, 2013.

A última atividade desenvolvida em sala de aula foi a elaboração de uma carta em que os alunos descreveram porque achavam necessário que as autoridades também estivessem sensibilizadas. Essa carta foi entregue à diretora auxiliar da escola com o pedido de que a mesma fosse encaminhada ao secretário de meio ambiente do município. 
Ao final das atividades de sensibilização, o questionário foi reaplicado aos alunos com a finalidade de identificar mudança nos conhecimentos adquiridos por eles após a realização das atividades.

\section{RESULTADOS E DISCUSSÃO}

"É inegável que a educação ambiental contribui significativamente para a proteção do meio ambiente e a melhoria da qualidade de vida" (DIAS, 1992). E como prova disso podemos ver os resultados obtidos ao final das atividades, em que foi possível observar uma melhora significativa em relação à percepção ambiental dos alunos quanto aos recursos hídricos de suas comunidades, conforme gráficos representados abaixo.

A necessidade de desenvolver hábitos responsáveis quanto ao uso da água, assim como de sua preservação, aponta a educação ambiental como um caminho eficaz nesta conquista.

Na primeira questão, sobre a origem da água utilizada nas casas, a maioria das respostas revela que os alunos mudaram os conceitos e percepção que possuíam e, para complementar, foi perguntado "se sim, onde?", a maior parte das respostas encontradas foram poço e rua, com $39 \%$ e $26 \%$ respectivamente. Após as atividades desenvolvidas, $55 \%$ dos alunos, portanto, a maioria respondeu nascentes conforme demonstrado no Gráfico 1.

As respostas obtidas nesta questão foram motivadas pelas atividades de resgate da vivência de cada aluno, pois, tiveram oportunidade de relatar de onde vem a água de suas casas. A variedade das respostas deve-se ao fato de os alunos morarem em áreas rurais e urbanas. 
Figura 4. Você sabe de onde vem a água que utilizamos em nossas casas? Se sim, onde?

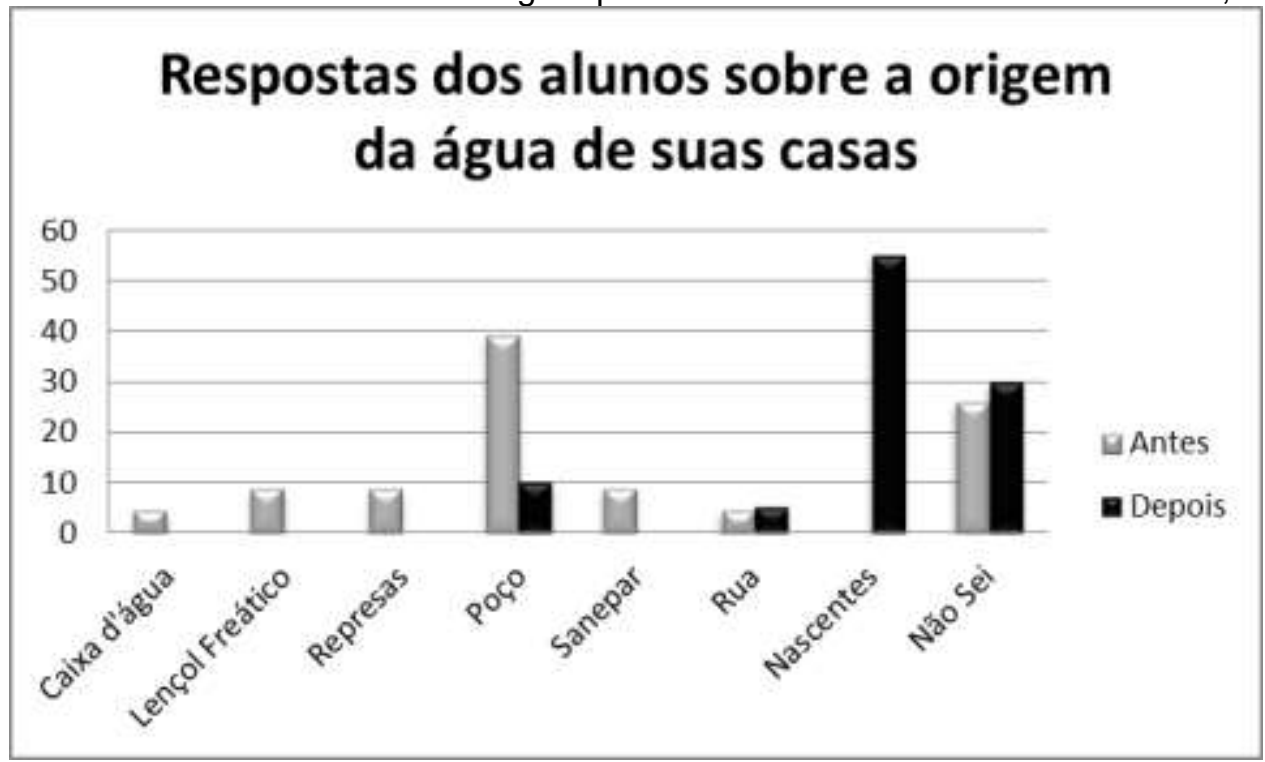

Fonte: Autoria própria, 2013.

Por outro lado, a porcentagem de alunos que responderam que não sabiam aumentou de $26 \%$ para $30 \%$, porém, uma diferença pequena quando se compara à porcentagem de alunos que responderam "das nascentes". Ressalte-se que a educação ambiental é uma atitude e como tal de difícil alteração num espaço curto de tempo.

Nas respostas em que apareceram itens como "caixa d'água", "lençol freático", "represas" e "Sanepar", não pontuaram no segundo questionário, demonstrando que as atividades de "educação ambiental propiciam o aumento de conhecimentos, mudança de valores e aperfeiçoamento de habilidades, condições básicas para estimular maior integração e harmonia dos indivíduos com o meio ambiente" (PÁDUA e TABANEZ, 1998 apud JACOBI, p.196, 2003,).

$\mathrm{Na}$ segunda pergunta os alunos foram questionados se o desmatamento pode prejudicar os recursos hídricos. A grande maioria dos alunos, 78\% responderam que "não sabiam", 13\% responderam "sim" e 9\% "não". Este é um resultado preocupante, pois é importante saber que:

\footnotetext{
"Quando retiramos a cobertura vegetal de um lugar, deixamos o solo desprotegido. A capacidade do terreno de reter a água da chuva é diminuída e esta passa a escorrer muito rápido, arrastando a camada superficial do solo. Além de se iniciar um processo de erosão e de perda da fertilidade do solo, os materiais arrastados com a água vão se acumular no fundo de rios, lagos e fontes, deixando o leito do rio cada vez mais raso, ou seja, ocasionando o seu assoreamento" (WWF, 2006).
} 
Figura 5. Você acha que o desmatamento prejudica as nascentes, rios e lagos?

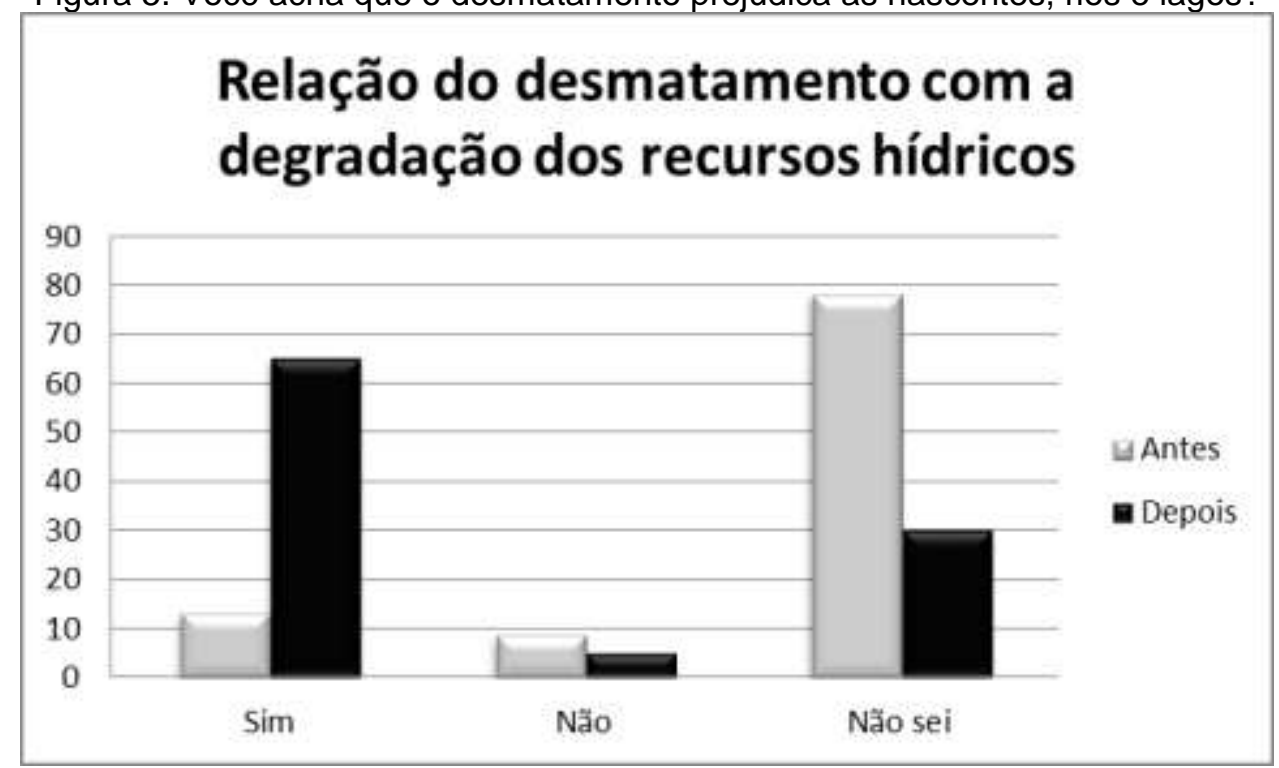

Fonte: Autoria própria, 2013.

A reaplicação do questionário revelou uma grande diferença em todas as alternativas, pois, a resposta "não sei" apareceu com uma porcentagem de $30 \%$, ou seja, $48 \%$ a menos que no inicio da pesquisa. A quantidade de alunos que responderam "sim" passou de $13 \%$ para $65 \%$ e os que responderam "não" de $9 \%$ para $5 \%$. Esses resultados sugerem que dos alunos que pensavam não haver relação entre desmatamento e degradação dos corpos hídricos, uma grande parte deles mudou sua concepção após as atividades. Trata-se de uma evolução bastante significativa neste conceito. Segundo o Código Florestal Brasileiro, deve-se preservar em áreas de nascentes no mínimo 50 metros de mata ciliar, no entanto em propriedades rurais não se respeita essa extensão, visando aumentar a área produtiva (MELO et al. 2011 p. 23 apud BRASIL, 1989).

Quando questionados se a mata ciliar é importante, na terceira questão, no momento inicial da pesquisa, os alunos que responderam "não saber" totalizaram $74 \%, 22 \%$ responderam "sim" e $4 \%$ "não". 
Figura 6. A mata ciliar é importante?

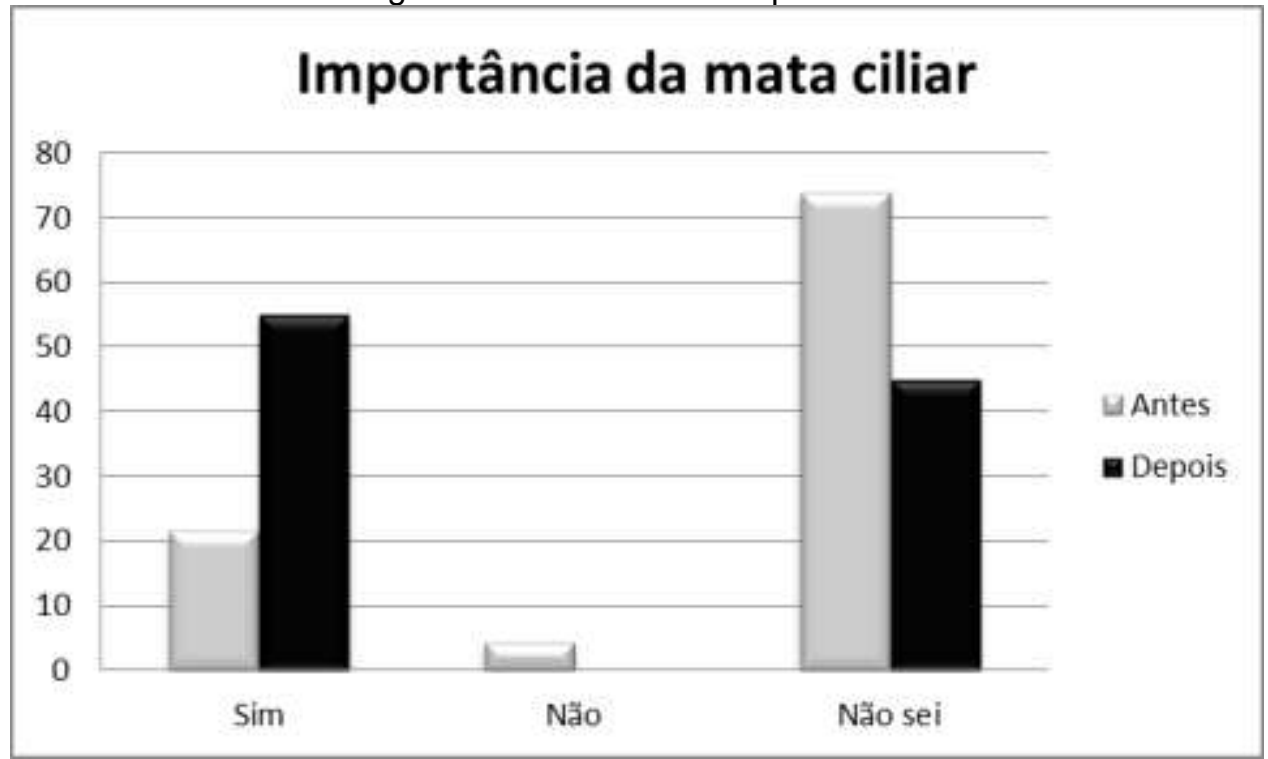

Fonte: Autoria própria, 2013.

Com a realização das atividades, a porcentagem de alunos que dizia não saber se a mata ciliar é importante foi de $45 \%$, a resposta "sim" apareceu com o percentual de $55 \%$, e a resposta "não", foi nula. Conforme observado no Gráfico 3.

Ao final da palestra alguns alunos fizeram alguns comentários como: - "Se cortar as árvores, o rio vai ficando mais baixo e mais largo". Nesse caso o aluno conseguiu relacionar a retirada das matas ciliares com o assoreamento dos rios. $\mathrm{Ou}$, em outro comentário do aluno: - "É importante preservar as nascentes, porque elas fornecem a água".

Tais questionamentos sugerem que houve interesse e, dessa forma, aumentando a chance de haver mudança também nesse conceito. Demonstrando uma preocupação em relação às nascentes, pois:

\footnotetext{
"As matas ciliares constituem um dos principais alvos de degradação pelo homem (...) contribuem tanto para diminuir a ocorrência do escoamento superficial, que pode causar erosão e arraste de nutrientes e sedimentos para os cursos d'água, quanto desempenhar um efeito de filtragem superficial e subsuperficial dos fluxos de água para os canais" (MELO et al. 2011).
}

$\mathrm{Na}$ quarta questão, os alunos deveriam responder se achavam que a agricultura prejudicava os nossos recursos hídricos. As respostas, nas duas etapas da pesquisa, revelam que houve melhora nos conceitos após as atividades de sensibilização. 
Dos alunos que responderam o primeiro questionário $65 \%$ afirmaram que a agricultura pode prejudicar as nascentes, já demonstrando um bom índice de informação, a porcentagem aumentou para $85 \%$ após as atividades.

Figura 7. Você acha que a agricultura pode prejudicar uma nascente, rio ou lago?

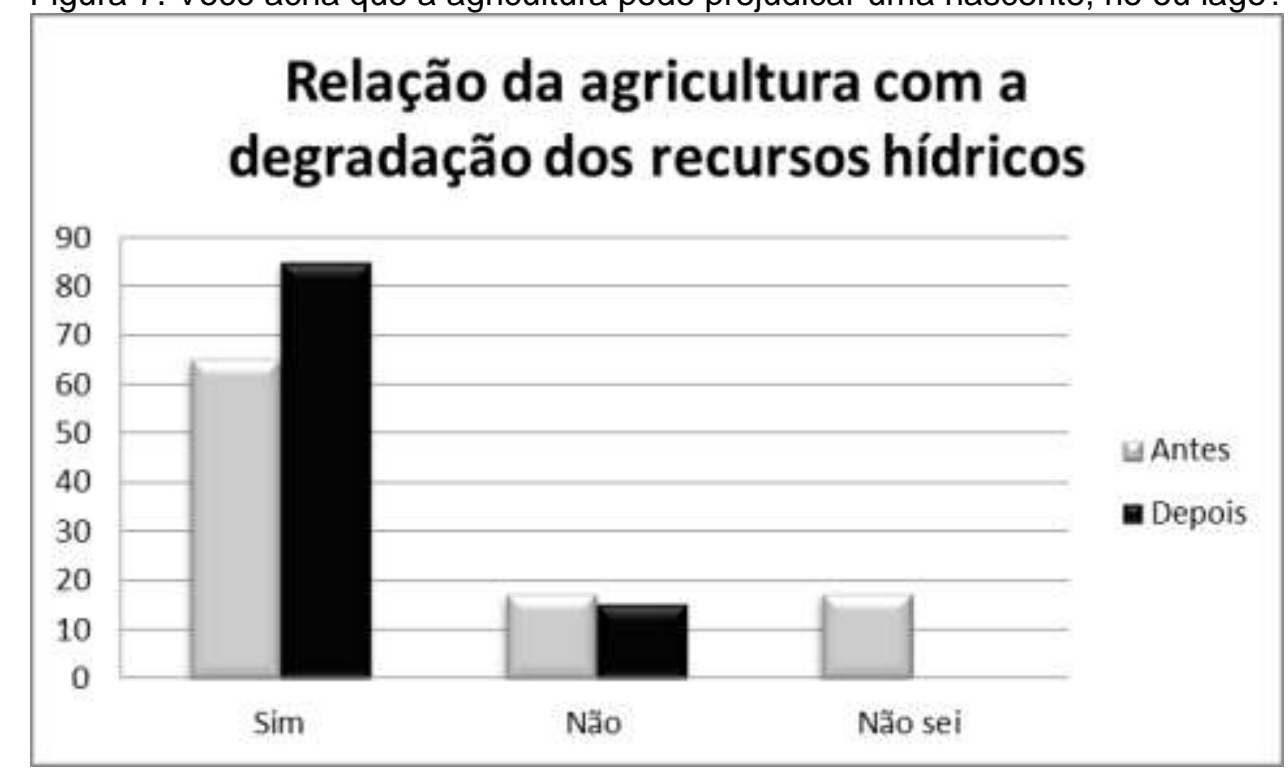

Fonte: Autoria própria, 2013.

O número de alunos que expuseram que a agricultura não prejudicava os recursos hídricos que antes era de $17 \%$ passou a ser de $15 \%$, diferença considerada pequena, mas, de relevância para a pesquisa. A porcentagem dos alunos que diziam não saber, que antes era $17 \%$, no segundo questionário, essa resposta não apareceu. Sugerindo que, de alguma forma, todos haviam identificado que a agricultura tem influência negativa sobre os recursos hídricos. Como pode ser analisado no Gráfico 4.

Mesmo sabendo que a retirada da mata ciliar tem influência na quantidade e na qualidade da água das nascentes, Coelho (2012) afirma que grande parte da área desmatada é consequência da ausência de locais apropriados para cultivar e garantir o sustento de varias famílias.

A última questão serviu como forma de complementar a questão anterior, buscando identificar como os alunos entendiam que agricultura poderia influenciar um corpo hídrico, deixando-os livres para respondê-la como quisessem.

Nesta questão as respostas obtidas, foram bastante variadas nos dois momentos da pesquisa, havendo uma porcentagem alta de alunos que não 
responderam no primeiro questionário, mais especificamente $35 \%$, e que passou a ser de apenas $10 \%$ ao final das atividades.

A resposta "fertilizantes", que teve porcentagem de $35 \%$, agora foi nula e a resposta "retirada da mata ciliar" que antes não havia aparecido, agora foi de $5 \%$.

Os agrotóxicos mencionados em $22 \%$ no primeiro questionário, agora totalizaram a grande maioria das respostas, $80 \%$. A quantidade de alunos que responderam que a agricultura não tem influência negativa sobre as nascentes passaram de $9 \%$ para $5 \%$, conforme o Gráfico 5.

Figura 8. Como a agricultura pode prejudicar uma nascente?

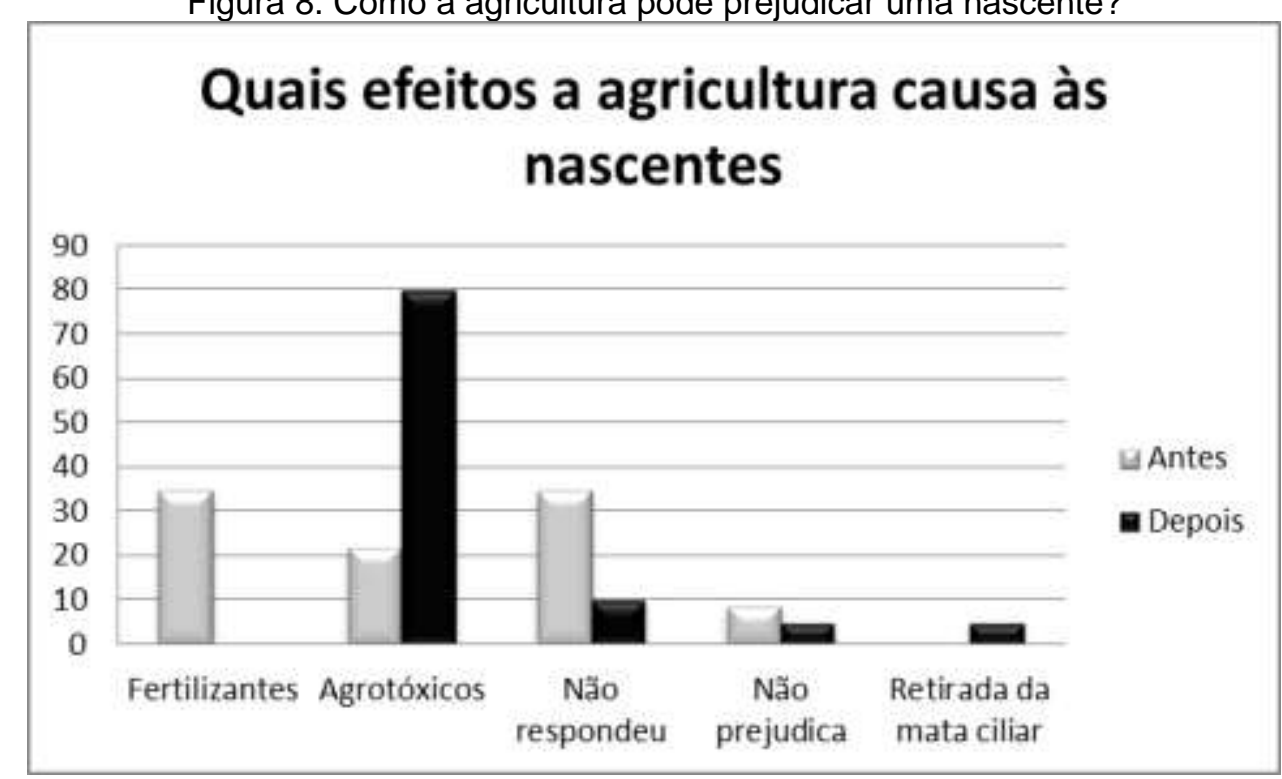

Fonte: Autoria própria, 2013.

Os resultados obtidos no primeiro questionário refletem a carência de ações de educação ambiental na escola, e também para a comunidade como um todo. Mas, no decorrer da pesquisa os alunos aprimoraram a percepção sobre o ambiente, com isso, "a educação ambiental na escola deve ser uma ideologia que conduza à melhoria da qualidade de vida" (SILVA et al. 2011).

"É com a visão do global e com um desejo de colaborar para um mundo melhor, que se pode propor um agir local. Daí a importância de integrar conhecimentos, valores e capacidades que podem levar a comportamentos condizentes com este novo pensar" (SÃO PAULO, 1999, p.4).

Segundo Silva et al. (2011) a consciência ambiental que os alunos desenvolvem na escola, é a principal arma para diminuir, ou mesmo extinguir, os impactos causados pela falta de conhecimento da população, como efeito das atividades desenvolvidas com os alunos, estes produziram uma carta direcionada ao 
secretário de meio ambiente do município, onde foi possível identificar mudanças na percepção durante a elaboração da carta, pois relacionaram a preservação dos recursos hídricos como uma ação essencial para a manutenção e qualidade da vida conforme exposta na Figura 4.

Figura 9. Carta elaborada pelos alunos com o auxílio da professora.

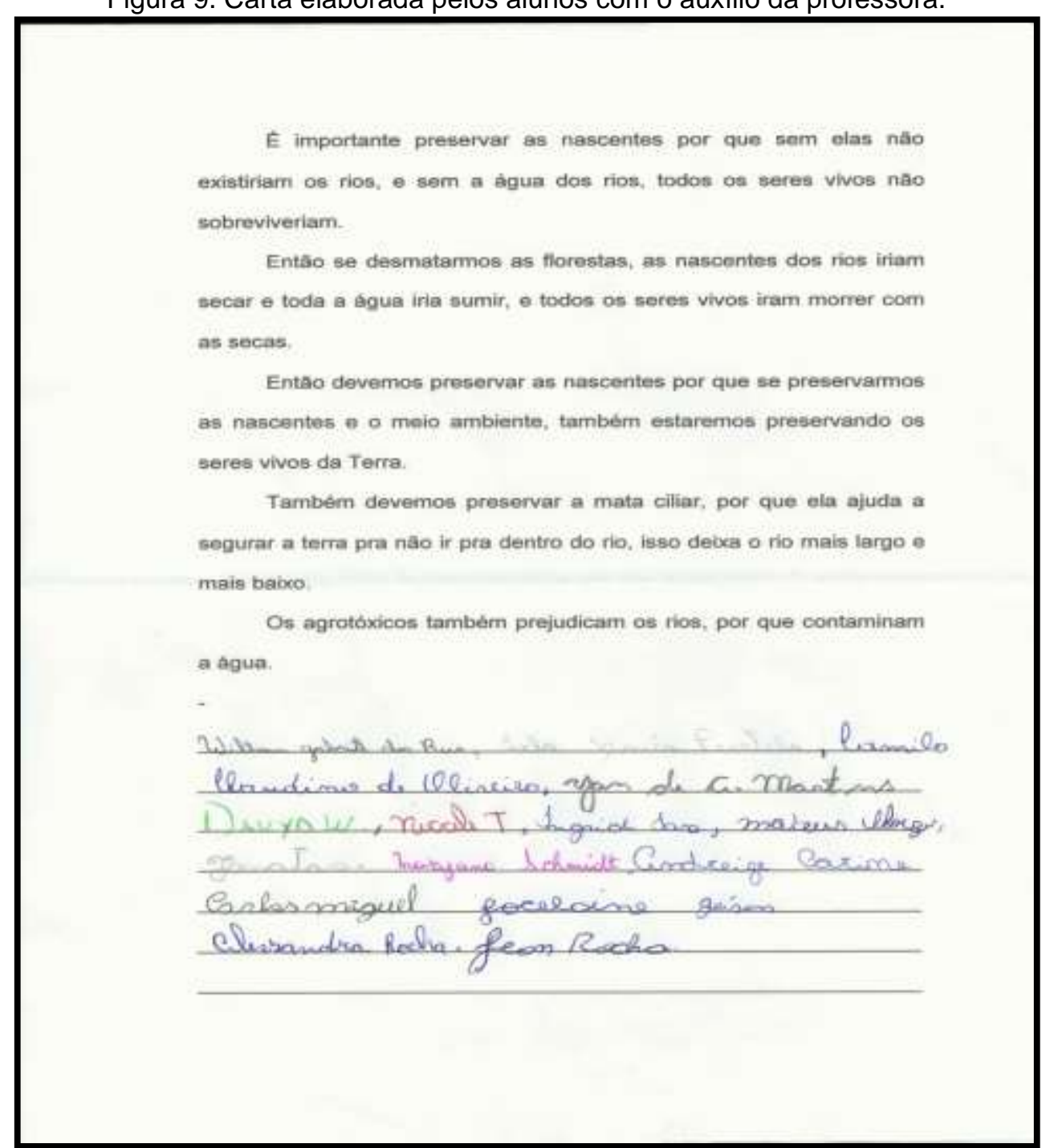

Fonte: Autoria própria (2013)

\section{CONSIDERAÇÕES FINAIS}

O presente trabalho reafirmou um diagnóstico que é preocupante, nas escolas públicas brasileiras, a baixa percepção dos alunos quanto à importância de se preservar os recursos hídricos. Por outro lado, foi possível demonstrar que, com um trabalho de sensibilização feito com base nas experiências pessoais dos alunos, 


\section{Periódico Eletrôntico

estes podem desenvolver um maior interesse e, consequentemente, buscar mais informações relacionadas ao tema.

Os resultados da pesquisa já eram esperados, mas, de uma forma menos significativa, tendo em vista que em todas as perguntas houve evolução bastante grande na percepção dos alunos.

Os resultados desta pesquisa sugerem que com a educação ambiental na escola, baseada no cotidiano dos alunos, já é suficiente para que estes melhorem a percepção sobre os recursos hídricos de suas comunidades, e que talvez futuramente, quando forem adultos, tornem-se contribuintes para zelar para que os recursos naturais sejam utilizados de maneira sustentável, visando preservá-los, e assim, melhorar sua qualidade de vida.

\section{REFERÊNCIAS}

BRASIL. Ministério da Educação. Secretaria de Educação Fundamental. Parâmetros Curriculares Nacionais. Temas Transversais. Brasília, DF, 1988.

CALHEIROS, R. O. et al. Preservação e Recuperação das Nascentes (de água e de vida) 1. ed. Piracicaba: DAEE, 2004.

COELHO, A. A. Percepção ambiental dos moradores ribeirinhos do médio Itaperuçu em Rosário-MA como subsídio a uma proposta de educação ambiental. Revbea, Rio Grande, v. 7, n. 2, p. 29-36, 2012.

DALZOTTO, E; CARNIATTO, I. Educação Ambiental: Atividades de percepção e instrução para a preservação de nascentes em áreas degradadas - Um desafio pra construção da agenda 21 local. Ponta Grossa, nov. 2009.

DIAS, G. F. Educação ambiental: princípios e prática. Brasília, v. 10, n. 49. jan./mar. 1991.

FRANK, B. Promoção da gestão de recursos hídricos em bacia hidrográfica: aprendizagem do projeto piava. Revista Eletrônica do Mestrado em Educação Ambiental, Rio Grande do Sul, v. especial, p.3, set. 2010.

JACOBI, P. Educação ambiental, cidadania e sustentabilidade. Cadernos de pesquisa. São Paulo, n. 118, p.189-205, mar. 2003.

LAYRARGUES, P. P. Muito além da natureza: educação ambiental e reprodução social. In: LOUREIRO, C.F.B. et al (Orgs.) Pensamento complexo, dialética e educação ambiental. São Paulo: Cortez. 2006. p. 72-103.

MELO, H. S. et al. Educação ambiental em uma comunidade rural: uma abordagem sobre a preservação de nascentes e matas ciliares. LATEC, Rio de Janeiro, v.1, n. 2, p. 21-35, jul/dez. 2011.

OLIVEIRA, E. M. et al. Percepção ambiental e sensibilização de alunos de colégio estadual sobre a preservação da nascente de um rio. Revista Eletrônica do Mestrado em Educação Ambiental, Rio Grande do Sul, v. 30, n. 1, p. 23-37, jan./jun. 2013. 
PINELI, A. A. P. et al. Educação ambiental e interdisciplinaridade na bacia hidrográfica do Ribeirão da Onça, sul de Minas Gerais. Revista Eletrônica do Mestrado em Educação Ambiental, Rio Grande do Sul, v. 25, p. 344-356, jul./dez. 2010.

RODRIGUES, A. S. L. et al. Análise das percepções ambientais e dos conhecimentos de alguns conceitos referentes às nascentes de rios revelados por jovens e adultos de uma escola no município de Ouro Preto, MG. R. bras. Bioci., Porto Alegre, v. 8, n. 4, p. 355-361, out./dez. 2010.

SÃO PAULO. Secretaria do Meio Ambiente. Conceitos para se fazer educação ambiental. São Paulo, SP, 1999.

SILVA, A. et al. Educação ambiental na escola municipal de tempo integral Santa Bárbara, no município de Palmas-TO. Tocantins, 2011. Disponível em: http://www.catolicato.edu.br/portal/portal/downloads/docs_gestaoambiental/projetos2011-1/1-

periodo/educacao_ambiental_na_escola_municipal_de_tempo_integral_santa_barbara_no_municipio de_palmas-to.pdf. Acesso em 27 set. 2013.

SILVA, A. B. C. G. et al. Como aplicar educação ambiental no dia a dia de uma escola pública. LATEC, Rio de Janeiro, v. 1, n.1, p. 1-16, jan/jun. 2011.

WWF. Cadernos de Educação Ambiental Água para Vida, Água para Todos: Livro das Águas. Brasília: Laborprint, 2006, p.16. 